\title{
HIGH RIPPLES REDUCTION IN DTC OF INDUCTION MOTOR BY USING A NEW REDUCED SWITCHING TABLE
}

\author{
Bachir Mokhtari * Mohamed F. Benkhoris ${ }^{* *}$
}

\begin{abstract}
The direct torque and flux control (DTC) of electrical motors is characterized by ripples of torque and flux. Among the many solutions proposed to reduce them is to use modified switching tables which is very advantageous; because its implementation is easy and requires no additional cost compared to other solutions. This paper proposes a new reduced switching table (RST) to improve the DTC by reducing harmful ripples of torque and flux. This new switching table is smaller than the conventional one (CST) and depends principally at the flux error. This solution is studied by simulation under Matlab/Simulink and experimentally validated on a testbed with DSPACE1103. The results obtained of a DTC with RST applied to a three-phase induction motor (IM) show a good improvement and an effectiveness of proposed solution, the torque ripple decreases about $47 \%$ and $3 \%$ for the stator flux compared with a basic DTC.

K e y w or d s: DTC, IM, CST, RST, torque ripple, flux ripple
\end{abstract}

\section{INTRODUCTION}

For a long time, reducing torque and flux ripples DTC has been a very rich field of research. However, we can divide this research into two areas, the first using the modified selection tables [1-6], and the use of smart technologies, it is the Software modification. The second axis is pointed on the Hardware side, such as, using multilevel inverters [7-10].

The second solution, despites its results and improvements that can be achieved, has the disadvantage of overcoming cost, and timing constraints during implantation. On the other hand, the first solution does not have these drawbacks, but it is a bit narrow at the research level. In [1], several studies were presented in the same subject with interesting results.

We propose in the present work, a novel switching table, extracted from the conventional one. The results will be compared to those obtained by conventional DTC selector, to show his improvement. The platform code developed in this study is based on the validation presented in [1].

The IM is associated with a static inverter constitutes a variable speed transmission of which the industrial use or general public does not cease growing.

Several works have led to the implementation of techniques of control for the IM. The vector control based on transitory and/or dynamic models of the machine has been developed.

This type of control makes it possible to have a faster dynamic response and a better precision of controlled parameters [1].
DTC was introduced in 1985/86 by Takahashi and Depenbrock especially for the asynchronous $[11,12]$ and after for synchronous machines [13-16]. The main advantages of DTC are the simple control scheme; without using current loops or a pulse width modulation (PWM) modulator, the control does not require coordinate transformation between the stationary frame and synchronous frame, moreover DTC is not sensitive to parameters variations except stator resistor [15].

In classical DTC, the employment of the hysteresis controllers to regulate the stator magnetic flux and torque is natural to have high torque ripples and variable switching frequency, which is varying with speed, load torque, selected hysteresis bands and difficulty to control torque and flux at very low speed $[11,12]$.

Applied a voltage vector to increase a torque or a stator flux, is logical, because the IM or any motor must absorb energies to develop a movement, but to stop doing, it is not necessary to apply a voltage again.

This is the idea of this work, to let the motor decrease the control greatness without intervention. When a voltage vector is applied to increase the torque or the flux, a moment after, the same vector will be the cause of decrease, because the flux change his position and move to next area (sector). This study is devoted to the modelling of the studied induction motor and presentation of a conventional DTC. We present the proposed switching table as a solution to reducing the torque and flux ripples. Finally, the results are presented and discussed.

\footnotetext{
* LEDMaSD Laboratory, Electrical Engineering Department, Laghouat University, BP 37G, Ghardaia Street, Laghouat (03000), Algeria, mokhtari71@yahoo.fr, ba.mokhtari@mail.lagh-univ.dz; ${ }^{* *}$ CRTT, IREENA, Saint Nazaire, Polytech'Nantes, France, mohamedfouad.benkhoris@univ-nantes.fr
} 


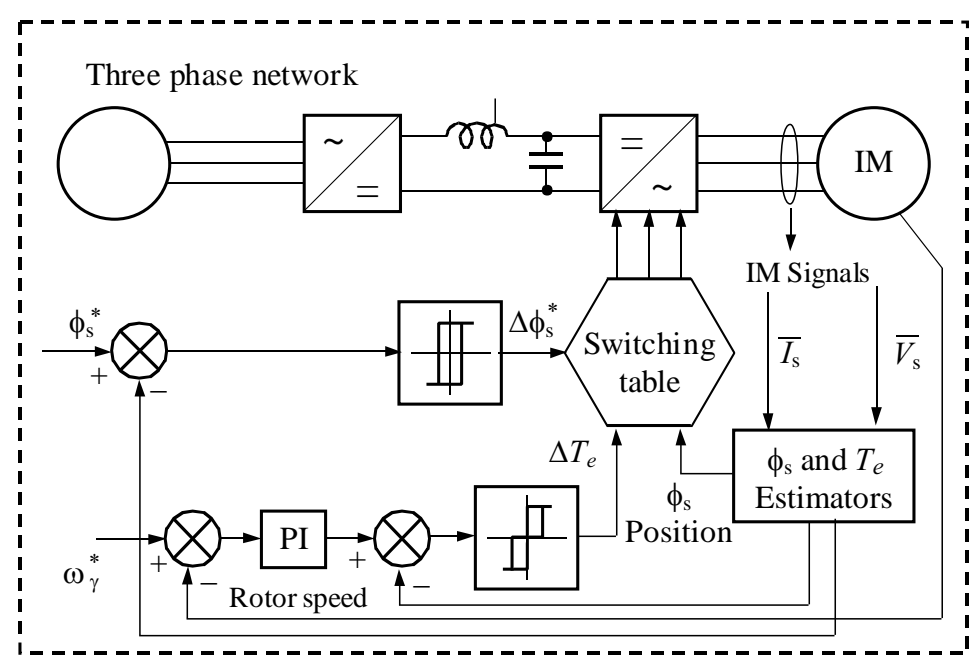

Fig. 1. Block Diagram of a Conventional DTC

\section{IM MODEL}

This study keeps the same IM classical model used in [1]. So we remind here the equations that describe the adopted model. We can thus write the stator and rotor flux equations in the reference frame of stator in the following form

$$
\dot{X}=A X+B U
$$

such as

$$
\begin{gathered}
X=\left[\begin{array}{llll}
i_{\alpha s} & i_{\beta s} & \phi_{\alpha s} & \phi_{\beta s}
\end{array}\right]^{t}, U=\left[\begin{array}{ccc}
\nu_{\alpha s} & \nu_{\beta s}
\end{array}\right]^{t} \\
A=\left[\begin{array}{cccc}
-\frac{1}{\sigma}\left(\frac{1}{T_{r}}+\frac{1}{T_{s}}\right) & -\omega_{r} & \frac{1}{\sigma L_{s} T_{r}} & \frac{\omega_{r}}{\sigma L_{s}} \\
\omega_{r} & -\frac{1}{\sigma}\left(\frac{1}{T_{r}}+\frac{1}{T_{s}}\right) & -\frac{\omega_{r}}{\sigma L_{s}} & \frac{1}{\sigma L_{s} T_{r}} \\
-r_{s} & 0 & 0 & 0 \\
0 & -r_{s} & 0 & 0
\end{array}\right]
\end{gathered}
$$$$
B=\left[\begin{array}{cc}
\frac{1}{\sigma L_{s}} & 0 \\
0 & \frac{1}{\sigma L_{s}} \\
1 & 0 \\
0 & 1
\end{array}\right], \sigma=1-\frac{m^{2}}{L_{s} L_{r}}, T_{s}=\frac{L_{s}}{r_{s}}, T_{r}=\frac{L_{r}}{r_{r}}
$$

where

$\omega_{r}=p \Omega:$ rotor speed,

$i_{s}:$ stator current

$\varphi_{s}:$ stator electromagnetic flux,

$v_{s}:$ stator voltage vector,

$r_{s}:$ stator resistance,

$L_{s, r}:$ stator or rotor inductance,

$m$ : mutual inductance.

In addition, the electromagnetic torque can be expressed by

$$
T_{e}=\frac{3}{2} p\left(\varphi_{\alpha s} i_{\beta s}-\varphi_{\beta s} i_{\alpha s}\right) .
$$

The mechanical equation of the motor can be expressed as

$$
J \dot{\Omega}=T_{e}-T_{r}-f_{r} \Omega_{r} .
$$

With $p$ is a magnetic pole pairs, $J$ is the moment of inertia, $T_{e}$ is the electromagnetic Torque, $T_{r}$ is the load Torque and $f_{r}$ is the friction coefficient.

\section{CONVENTIONAL DTC}

Maybe it is still necessary to recall the principle of conventional DTC shown in Fig. 1, it is consist of directly controlling the turn $\mathrm{OFF}$ or turn $\mathrm{ON}$ of the inverter switches on calculated values of stator flux and torque from (5) and (6).

The changes of state of the switches are linked to the changes in electromagnetic state motor.

The reference frame related to the stator makes it possible to estimate flux and torque, and the position of flux stator.

The aim of the switches control is to force the stator flux vector to join its reference [10-11].

The two components of stator flux are estimated by the following expression

$$
\begin{aligned}
& \varphi_{s \alpha}=\int_{0}^{t}\left(v_{s \alpha}-r_{s} I_{s \alpha}\right) \mathrm{d} t, \\
& \varphi_{s \beta}=\int_{0}^{t}\left(v_{s \beta}-r_{s} I_{s \beta}\right) \mathrm{d} t .
\end{aligned}
$$

So the DTC is deduced from the two approximations given by

$$
\begin{gathered}
\bar{\varphi}_{s}(k+1) \approx \bar{\varphi}_{s}(k)+\bar{V}_{s} T_{E} \rightarrow \Delta \bar{\varphi}_{s} \approx \bar{V}_{s} T_{E} \\
T_{e}=k\left(\bar{\varphi}_{s}+\bar{\varphi}_{r}^{\prime}\right)=k\left|\bar{\varphi}_{s}\right|\left|\bar{\varphi}_{r}^{\prime}\right| \sin \delta .
\end{gathered}
$$

The stator flux magnitude and his position are given by

$$
\hat{\varphi}_{s}=\sqrt{\hat{\varphi}_{s \alpha}^{2}+\hat{\varphi}_{s \beta}^{2}}, \quad \angle \hat{\varphi}_{s}=\operatorname{arctg} \frac{\hat{\varphi}_{s \beta}}{\hat{\varphi}_{s \alpha}} .
$$

Figure 2 presents the diagram of implementation of the DTC by using a DSPACE1103. All the components of this testbed will be cited later. 


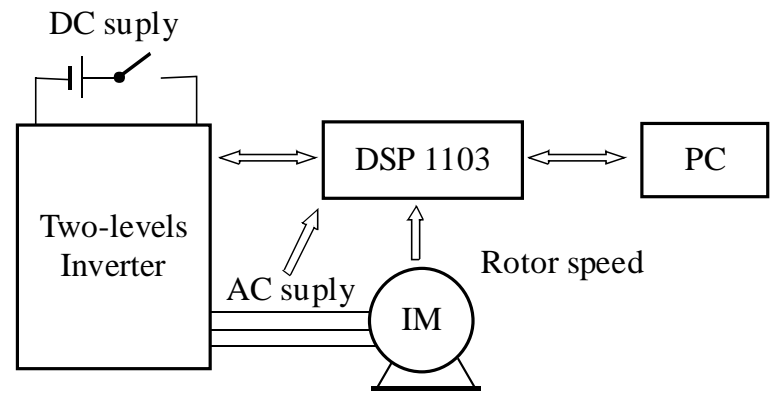

Fig. 2. Diagram of an implementation of a DTC applied to the IM

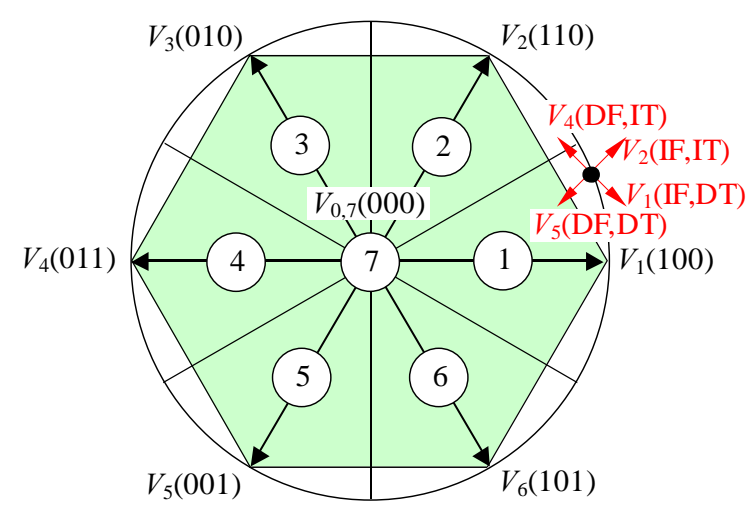

Fig. 3. Different vectors of stator voltages provided by a two levels inverter, (100): (1:inverter switch is ON, 0: for OFF) I(D)F: increase (decrease) of flux magnitude, I(D)T: increase (decrease) of torque

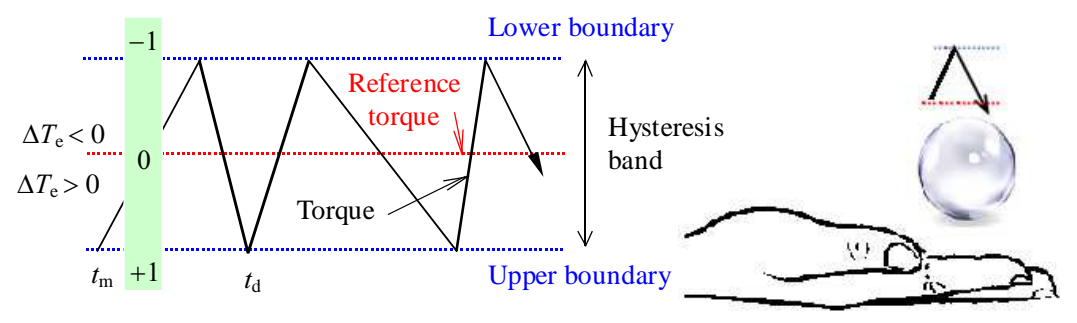

Fig. 4. Torque ripples in hysteresis band

Table 1. Switching table for a conventional DTC

\begin{tabular}{cccccccc}
\hline$\Delta \varphi_{s}$ & $\Delta T_{e}$ & $S_{1}$ & $S_{2}$ & $S_{3}$ & $S_{4}$ & $S_{5}$ & $S_{6}$ \\
\hline \multirow{3}{*}{1} & 1 & 110 & 010 & 011 & 001 & 101 & 100 \\
& 0 & 000 & 000 & 000 & 000 & 000 & 000 \\
& -1 & 101 & 100 & 110 & 010 & 011 & 001 \\
\hline \multirow{3}{*}{0} & 1 & 010 & 011 & 001 & 101 & 100 & 110 \\
& 0 & 000 & 000 & 000 & 000 & 000 & 000 \\
& -1 & 001 & 101 & 100 & 110 & 010 & 011 \\
\hline
\end{tabular}

$S_{i=1, \ldots, 6}$ are localization sectors of the stator vector flux.

A two levels classical voltage inverter can achieve seven separate positions in the phase corresponding to the eight sequences of the voltage inverter [1].

These positions are illustrated in Fig. 3. In addition, Table 1 presents the conventional switching table CST and shows the sequences for each position.

The flux and torque are controlled by two comparators with hysteresis. The dynamics torque are generally faster than the flux then using a comparator hysteresis of several levels, is then justified to adjust the torque and minimize the switching frequency average [10-11].

\section{REDUCED SWITCHING TABLE}

The same principle of basic DTC control of the IM which is supplied by a two-level inverter is applied.
For the torque reached its reference, we must apply a voltage vector which increases until the time $t_{m}$ in Fig. 4.

Once the torque is in the hysteresis band, the application of zero voltage is maintained in this band. Thus, the torque increases but it exceeds the lower boundary only slightly. If the torque exceeds the upper boundary, you can restore it by applying only the vectors that increase and the zero voltage between $t_{m}$ and $t_{d}$ in Fig. 4.

A physical interpretation can be given to justify this strategy, assuming that any physical system tends to get rid of the energy obtained from an external source, by consummation or by changing it to another form of energy. So once the motor has enough energy to develop the desired torque, it is running stream will be in a position where the voltage vector applied no longer serves to increase the flux (the torque). It tends to decrease and this time, it is controlled by the upper boundary, if it exceeds it, the application of voltage vector corresponding to its increase will be applied. The lower boundary of overtaking is ensured by the natural behavior of the system (that is quite similar to an air bubble, to maintain it at top level, we must only push it to top, and don't interesting to his movement to down). This new reduced switching table is simpler than the conventional table; we use only two lines of the Table 2 (when we take only one direction of motor speed rotating).

The torque error is dominant if it is less than the upper boundary of the hysteresis band for positive speeds, and when it exceeds the lower boundary of the hysteresis band for the negative speed, while the flux error becomes dominant for other cases. 


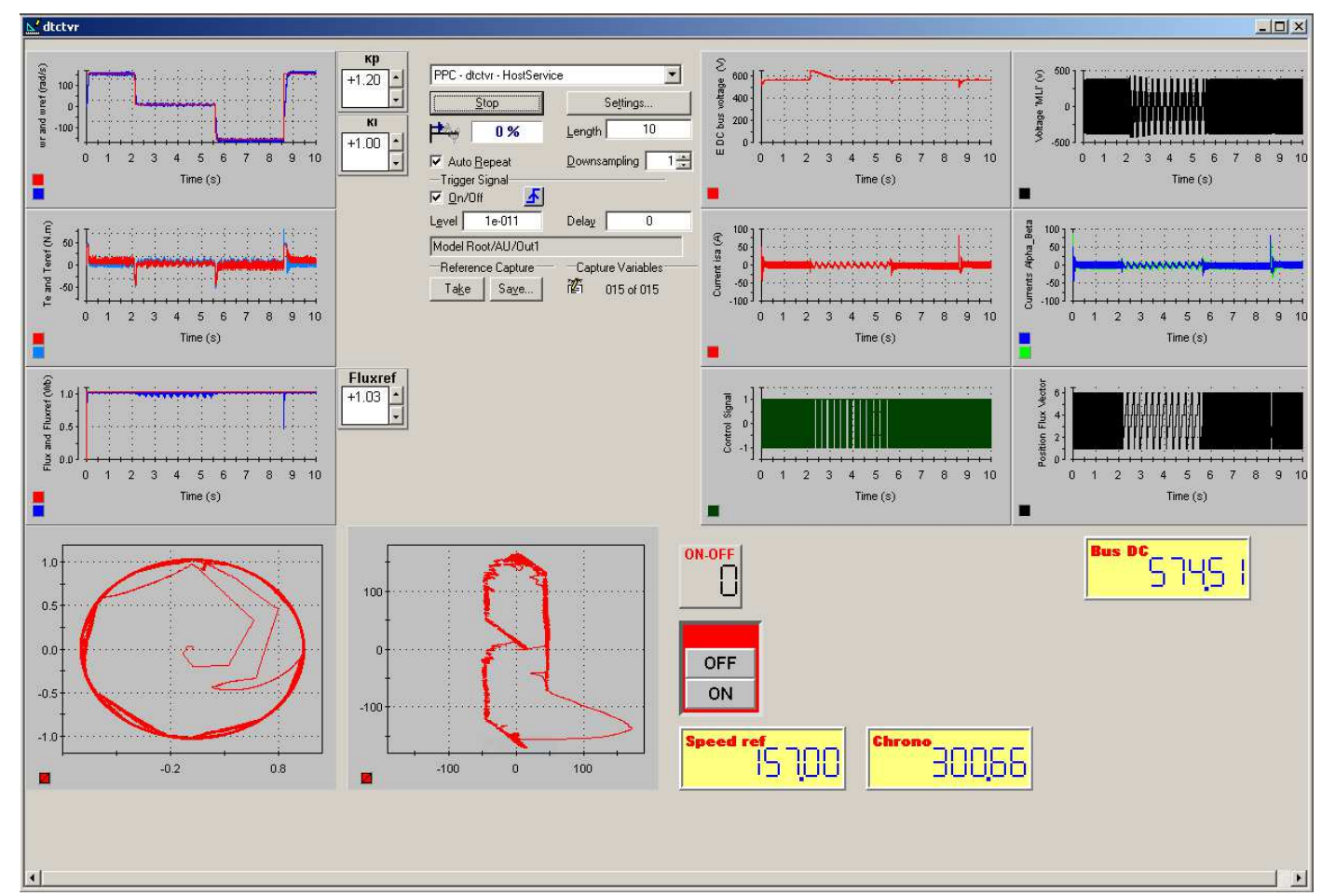

Fig. 5. Screen image for the RST validation

Electromagnetic torque respose $(\mathrm{Nm})$

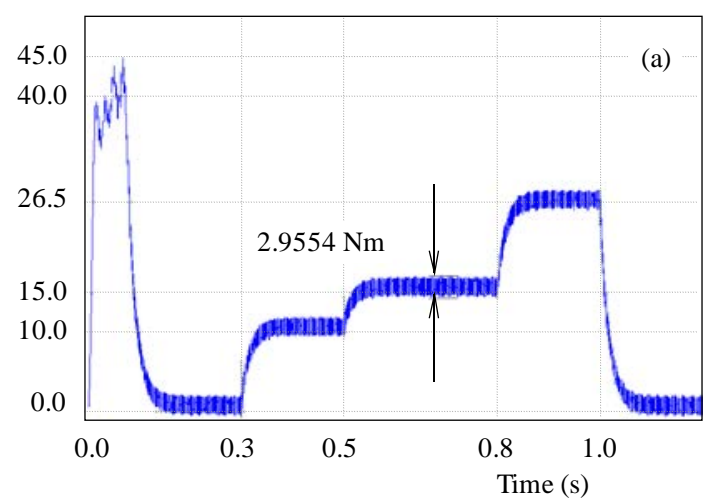

Electromagnetic torque respose $(\mathrm{Nm})$

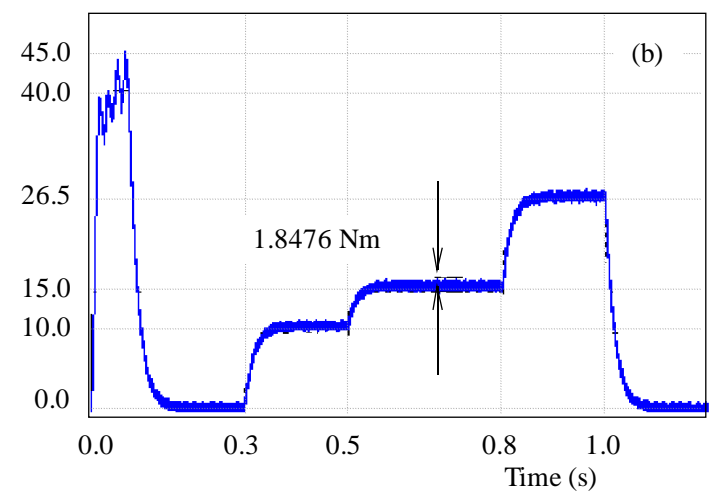

Fig. 6. Electromagnetic torque response: (a) - DTC with CST, (b) - DTC with RST

So, our proposed switching table is given by Table 2. 2) the load (PMSG),

Table 2. Reduced switching table RST of DTC

3) CPU: P3(X86 family 6, model 8, stepping 6), $866 \mathrm{MHz}$, 256 MO (Ram), VGA: Matrox Millinium G450 Dual head (32 MO), OS: Windows 2000 pro,

4) DSPACE: ISA, DSP1103 PPC controlled board,

\begin{tabular}{cccccccc}
\hline $\operatorname{sign}\left(\omega_{r}\right) \Delta T_{e}<U B$ & \multicolumn{8}{c}{$V_{0}$ (null voltage) } \\
Sectors $\rightarrow$ & & $S_{1}$ & $S_{2}$ & $S_{3}$ & $S_{4}$ & $S_{5}$ & $S_{6}$ \\
\hline counterclockwise & $\uparrow 1$ & $V_{2}$ & $V_{3}$ & $V_{4}$ & $V_{5}$ & $V_{6}$ & $V_{1}$ \\
$\omega_{r}>0$ & $\downarrow 0$ & $V_{3}$ & $V_{4}$ & $V_{5}$ & $V_{6}$ & $V_{6}$ & $V_{2}$ \\
\hline clockwise & $\uparrow 1$ & $V_{6}$ & $V_{1}$ & $V_{2}$ & $V_{3}$ & $V_{4}$ & $V_{5}$ \\
$\omega_{r}<0$ & $\downarrow 0$ & $V_{5}$ & $V_{6}$ & $V_{1}$ & $V_{2}$ & $V_{3}$ & $V_{4}$ \\
\hline
\end{tabular}

\section{EXPERIMENTAL AND} SIMULATION RESULTS

To validate the proposed solution a testbed was realized with the parts

1) induction motor (see Table 3 for parameters),

5) two levels voltage INVERTER ( $\max 100 \mathrm{KHz})$, IGBT (1200V-50A),

a. speed: universal DIGISINE, DHO5 [BEI-IDEACOD],

b. current: AM30N 10-100A/1V, (Input: $100 \mathrm{~A}$ peak $\max$, DC $100 \mathrm{kHz}$, output:100-10 $\mathrm{mV} / \mathrm{A}, 1 \mathrm{~V}$ peak $\max$,

c. voltage: differential DP1000 with two outputs 10-100.

A screen image has been taken when the ST proposed was being validated on a testbed; it is shown in Fig. 5 . for a simulation without load but at a variable speed. It is clearly that RST is stable and improves the control by DTC. 

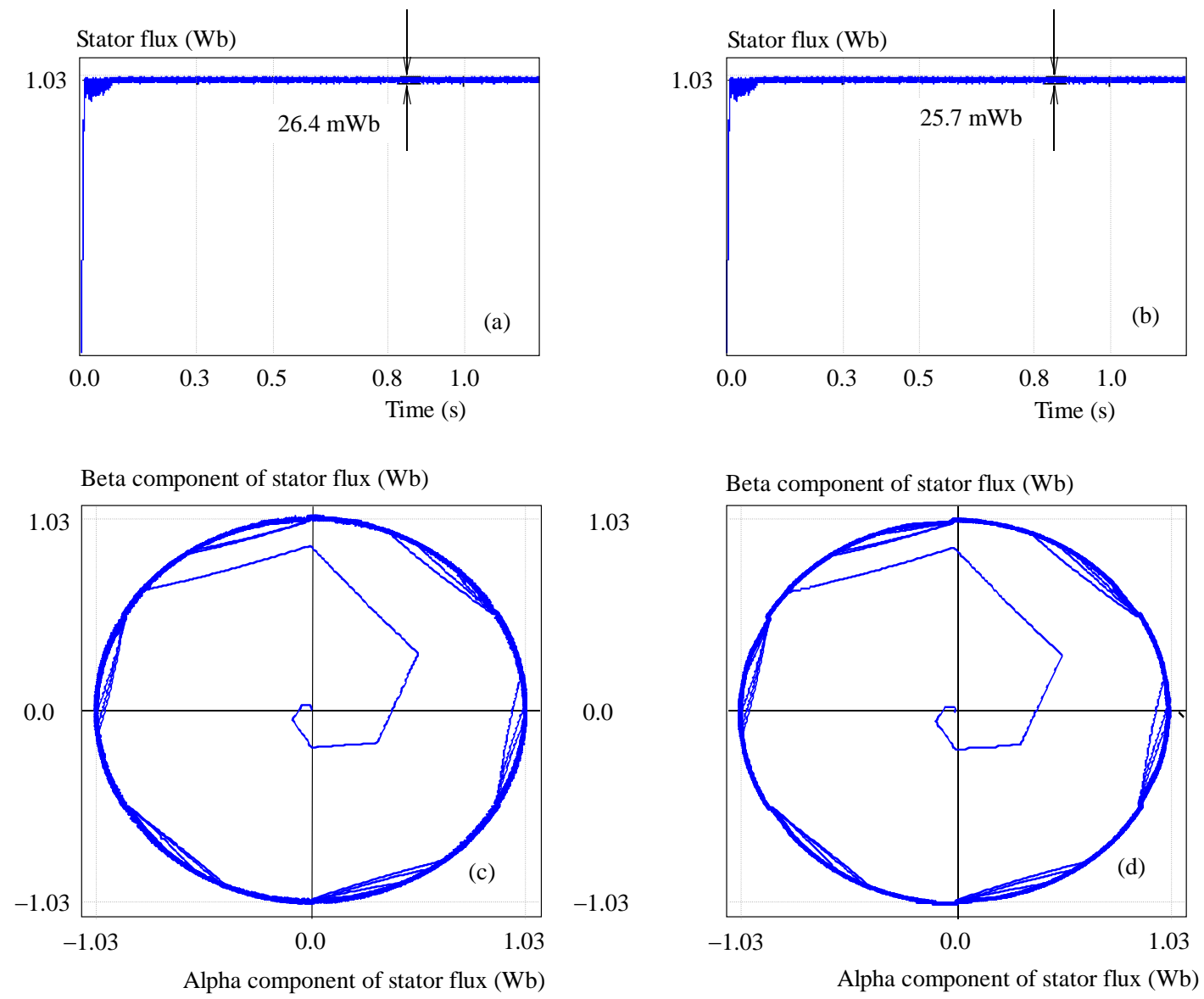

Fig. 7. Stator flux response: (a),(b) — magnitude stator flux for CST/RST, (c),(d) — position of stator flux

Table 3. Induction motor parameters used in study

\begin{tabular}{ll}
\hline Pole pairs & 2 \\
Rated power $\mathrm{kW}($ at $50 \mathrm{~Hz})$ & 4 \\
Rated voltage $(\mathrm{V})$ & $220 / 380$ \\
$R_{s}(\Omega)$ & 1.30 \\
$R_{r}(\Omega)$ & 0.91 \\
$L_{s, r}(\mathrm{H})$ & 0.19 \\
$M(\mathrm{H})$ & 0.18 \\
$J\left(\mathrm{~kg} \mathrm{~m}^{2}\right)$ & 0.009 \\
$f_{r}(\mathrm{~N} \mathrm{~m} \mathrm{~s} / \mathrm{rad})$ & 0.03 \\
\hline
\end{tabular}

Below, we can see a simulation of the RST with a load variation compared with a conventional ST in the same case. We turn the attention here, to the comparison between a DTC with CST and with RST. This study does not aim to show any traditional results but only who determine the improvement given by our proposition.

The movement is started without load, at $0.3 \mathrm{~s}$ the reference torque is $10 \mathrm{Nm}$, at $0.5 \mathrm{~s}$ it is increased to $15 \mathrm{Nm}$ and for 0.8 to $1 \mathrm{~s}$ it is increased to $26.5 \mathrm{Nm}$. It is clearly that the electromagnetic torque follows its reference properly.

Figure 6 shows an important minimization of torque ripples, about $47 \%$, when the new switching table RST is used. This percent is calculated by subtracting (value $\max$ - value min) in the two cases of switching tables, and we calculate the rapport.

As regards the stator flux in Fig. 7, we note a reduction of $3 \%$. This means that the proposed table provided a good improvement to the control by DTC especially the high minimization of torque ripples obtained.

In Fig. 8, we can see also that the stator current is stable and not perturbed by using the RST, so for the same electrical behaviour, we have an improved response of the control system.

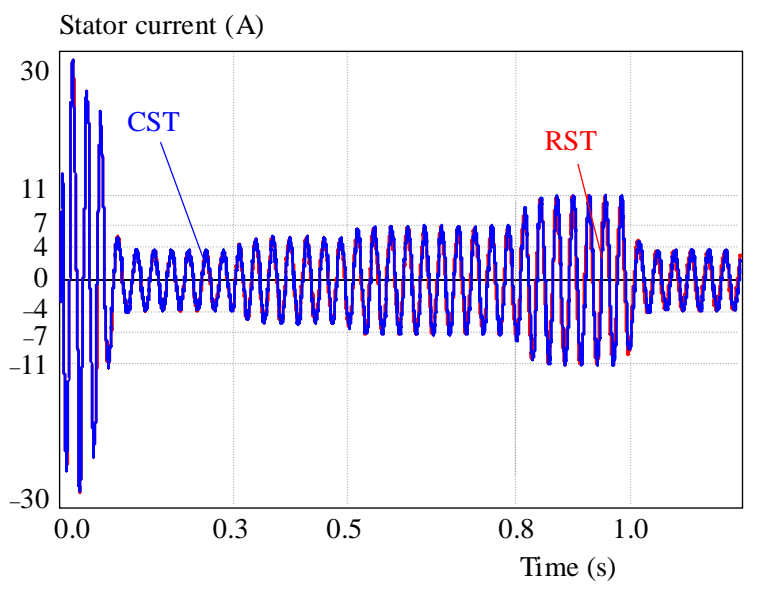

Fig. 8. Stator current of one phase 


\section{CONCLUSION}

In this paper, we have presented a novel and simple switching table of DTC applied to an induction motor, our aim was to reduce the torque ripples and so the acoustical noises.

This proposed table is smaller than the conventional one, this solution is very interesting because there is no added cost comparing with other solutions and it is easy to implant it on the same conventional testbed already present.

Results obtained show a good improvement of the DTC by an important reducing of the torque ripples about $47 \%$ and about $3 \%$ for the flux ripples.

In future work, we plan to use this new table to improve the control of an electric vehicle and also to a tracking system, and also improve the control by multilevel inverter as a three-level NPC.

\section{Acknowledgment}

This experimental study was realized within the CRTT (IREENA) in Saint-Nazaire, Nantes University. Any one of this organization, who have helped us, find here our thanks most distinguished, especially Mr Houari Azeddine and Mr Franck Judik.

\section{REFERENCES}

[1] MOKHTARI, B.-AMEUR, A.-MOKRANI, L.-AZOUI, A. -BENKHORIS, M. F. : Comparative Experimental Study of Three Switching Tables of a DTC Applied to an Induction Motor for a Tracking System, Journal of Electric Engineering 63 No. 3 (2012), 99-104.

[2] KUMAR, B. S.-GUPTA, R. A.-KUMAR, R.: 12-Sector Methodology of Torque Ripple Reduction in a Direct Torque Controlled Induction Motor Drive, SICE-ICASE International Joint Conference (Oct 18-21, 2006), in Bexco, Busan, Korea, pp. 3587-3592.

[3] SEBTAHMADI, S. S.-PIRASTEH, H.-KABOLI, S. H. A.RADAN, A.-MEKHILEF, S.: A 12-Sector Space Vector Switching Scheme for Performance Improvement of Matrix-Converter-Based DTC of IM Drive, IEEE Trans. Power Electron. 30 No. 7 (July 2015), 3804-3817.

[4] MEI, C. G.-PANDA, S. K.-XU, J. X.-LIM, K. W. : Direct Torque Control of Induction Motor-Variable Switching Sensors, IEEE-PEDS Conf. Rec. Hong Kong, July 1999, pp. 80-85.

[5] HAFEEZ, M.-UDDIN, M. N. : A New Torque Hysteresis Control Algorithm for Direct Torque Control of an IM Drive, IEEE International Electric Machines \& Drives Conf. (IEMDC), Niagara Falls, 15-18 May 2011, pp. 759-764.

[6] SINGH, B.-JAIN, S.-DWIVEDI, S. : Enhancement in Steady State and Dynamic Performance of Direct Torque Control Induction Motor Drive, Journal of Electrical Engineering, 64, No. 5 (2013), 283-290.

[7] GAnAtRA, D. H.-PANDYA, S. N. : Torque Ripple Minimization in Direct Torque Control Based Induction Motor Drive Using Multilevel Inverter, IEEE Students' Conf. on Electrical, Electronics and Computer Science (SCEECS), Bhopal, 1-2 March 2012, pp. 1-5.

[8] YONGCHANG, Z.-JIANGUO, Z.-ZHENGMING, Z.-WEI, X.-DORRELL, D. G. : An Improved Direct Torque Control for Three-Level Inverter-Fed Induction Motor Sensorless Drive, IEEE Trans. Power Electron. 27 No. 3 (Mar 2012), 1502-1513.

[9] MARTins, C.-ROBOAM, X.-MEYNARD, T. A.-CARYALHO, A. S.: Switching Frequency Imposition and Ripple Reduction in DTC Drives by Using a Multilevel Converter, IEEE Trans. Power Electron. 17 No. 2 (Mar 2002), 286-297.

[10] CIRRINCIONE, M.-PUCCI, M.-VitALE, G.: A Novel Direct Torque Control of an Induction Motor Drive with a Three-level Inverter, IEEE Bologna Power Tech. Conf., Italy, June 23-26 2003, pp. 7.

11] TAKAHASHI, I.-NOGUCHI, T. : A New Quick-Response and High-Efficiency Control Strategy of an Induction Motor, IEEE Trans. Ind. Appl IA-22 No. 5 (Sep-Oct 1986), 820-827.

12] TAKAHASHI, I.-OHMORI, Y.: High-Performance Direct Torque Control of an Induction Motor, IEEE Trans. Ind. Appl. 25 (Mar-Apr 1989), 257-264.

[13] TON, D. D.-HAN, H. C.-JIN-WOO, J.: Nonlinear Optimal DTC Design and Stability Analysis for Interior Permanent Magnet Synchronous Motor Drives, IEEE/ASME Trans. Mechatron. 20 No. 6 (Dec 2015), 2716-2725.

[14] AMEUR, A.-MOKHTARI, B.-MOKRANI, L.-AZOUI, B. -ESSOUNBOULI, N.-HAMZAOUI, A. : An Improved Sliding Mode Observer for Speed Sensorless Direct Torque Control of PMSM Drive with a Three-Level NPC Inverter Based Speed and Stator Resistance Estimator, Journal of Electric Engineering 61 No. 4 (2010), 1-9.

[15] ERRAMI, Y.-OUASSAID, M.-CHERKAOUI, M.-MAAROUFI, M. : Variable Structure Sliding Mode Control and Direct Torque Control of Wind Power Generation System Based on the PM Synchronous Generator, Journal of Electrical Engineering 66 No. 3 (2015), 121-131.

[16] BOUDANA, D.-NEZLI, L.-TLEMYANI, A.-MAHMOUDI, M. O.-TADJINE, M. : Robust DTC Based on Adaptive Fuzzy Control of Double Star Synchronous Machine Drive with Fixed Switching Frequency, Journal of Electrical Engineering 63 No. 3 (2012), 133-143.

Received 17 February 2016

Bachir Mokhtari was born in Laghouat, Algeria, in 1971. He received the Engineer degree in Electrical Machine from the Electrical Engineering Department of Laghouat University, in 1997, and then he received the Magister and the DrSc degrees in Electrical Engineering from the Electrical Engineering Department of Batna University, in 2004 and 2014 respectively. Since 2014 he is an Associate Professor in the Department of Electrical Engineering, Faculty of Technology of Laghouat University. His research interest is the Electrical Machine Control and the Renewable Energies.

Mohamed Fouad Benkhoris was born in Bou-sâada, Algeria, in 1963. He has studied at cole Nationale Polytechnique d'Alger (ENPA), Algeria, and received the Engineer degree in Electrical Engineering in 1986. In 1991, he obtained his PHD degree in Electrical Engineering at INP Lorraine (France) and the "HDR" (Habilitation à diriger des recherches) in March 2004. From 1991, he is an Assistant Professor at the Department of Electrical Engineering, of Polytech'Nantes, France. Since 2006 he is Professor at Polytech'Nantes, France. He makes research activities at the laboratory IREENA Saint-Nazaire. His fields of interest are: Dynamical Modelling, Simulation and Control of Electrical Drives and Especially Multi-phase Drive, Multi-converters Systems and Embarked Network. 